\title{
The Empirical Research of Price Fluctuation Rules and Influence Factors with Fresh Produce Sequential Auction
}

\author{
Limei Cui \\ Qujing Normal University, Qujing 655011 \\ 756612367@qq.com
}

Keywords: Sequential auction; Fresh agricultural product; Price; Fluctuation trends

\begin{abstract}
Research the law of price fluctuations under the fresh agricultural sequential auction based on the auction theory; use Kunming International Flower Auction Centre (KIFA) as an example for empirical analysis. After appoint the study object which is the rose of $80 \mathrm{~cm}$ length for the B level (network) named Corolla and the study period, the price trends. Establish some reasonable assumptions factors, and then use the multiple linear regressions for analysis these variables. Eventually find that the previous auction price, auction duration, the buyer type (size) and the seller types (size) and other factors have a certain degree of influence on the auction price fluctuations.
\end{abstract}

\section{Introduction}

Sequential auction belongs to multi-object auctions that are multi objects being traded in sequence with an open price auction mechanism which have a rapid trading speed and a lower trading cost. Along with the developing of auction practice and auction theory, the market of western countries first found that sequential auction is very suit for trading fresh produce. By importing sequential auction can solve a lot of problems such as lower marketing efficiency, higher marketing cost and so on. It has many benefits for agricultural industrialization. However, because of the character that last transaction price will affect current transaction in sequential auction; the transaction price will generate a great fluctuate with other factors over time. Obviously, this transaction price fluctuate is disadvantageous for the auction participant. How to analysis the factors of influencing price formation and price fluctuate using the rule of price fluctuate to adopt reasonable measures control the price fluctuate or made it tend to smooth and steady is the mainly problem to be solved in this paper.

\section{The Fluctuation Rules of Fresh Produce Price in Sequential Auction}

The fluctuation rules of fresh produce price in sequential auction in this article are based on the long term auction practice of Kunming International Flower Auction Market which is short for KIFA. The KIFA was set up and put into operation at 2002; it is a large professional flower trading market and it engage in fresh flowers auction. Nowadays, the KIFA is become the biggest flower auction and trading market in China even in Asia. In this section, we will analyze the auction price fluctuation phenomenal in the KIFA. All the auction data are come from the transaction history database of KIFA, 5,621,604 transaction data from Dec 1st 2007 to Feb 2nd 2010.

According to the preliminary analysis of these almost six million data, we find there is a superfine rose named Carola in KIFA has the biggest transaction frequency and best trading volume and largest transaction amount while the trading class of Carola is class B and the length is $80 \mathrm{~cm}$. So this article chose the Carola with $80 \mathrm{~cm}$ length and B class as the mainly research object. And we choose the whole year data of 2008 and 2009 of KIFA for a deeply analyze in order to find out the rules and the influence of price fluctuation. 


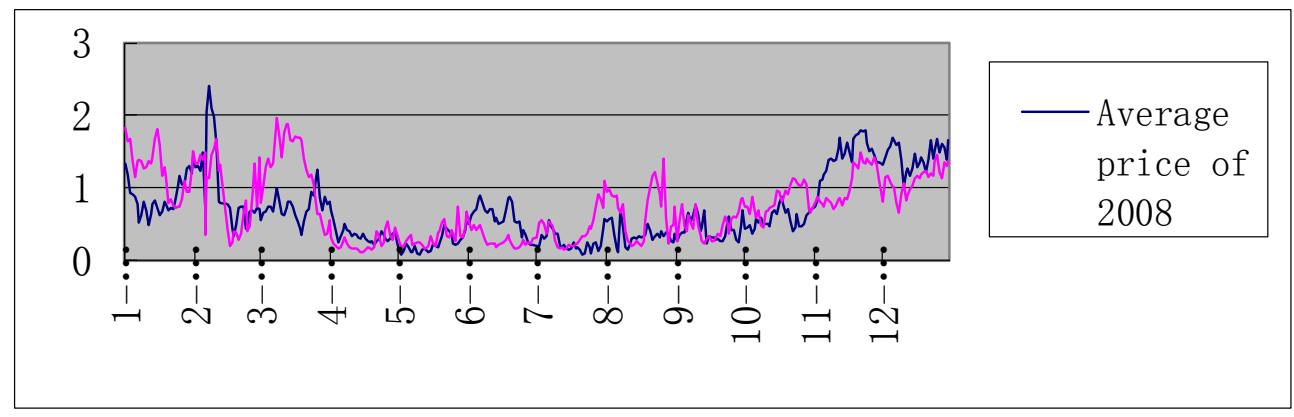

Figure 1. The average price fluctuation contrast of Carola with $80 \mathrm{~cm}$ length and B class between 2008 and 2009

The Fig. 1 directly shows that in every year, from May to August, the price fluctuation became stable. Analyze the data further; we calculate the mean value and standard deviation of Carola with $80 \mathrm{~cm}$ length and B class transaction price during every moth in the year of 2008 and 2009.

Table 1 The average price and standard deviation of Carola with $80 \mathrm{~cm}$ length and B class in each month of 2008

\begin{tabular}{lcccccccccccc}
\hline & Jan. & Feb. & Mar. & Apr. & May. & June. July. Aug. & Sept. & Oct. & Nov. & Dec. \\
\hline Avg. Price & 0.87 & 1.04 & 0.74 & 0.37 & 0.22 & 0.58 & 0.24 & 0.35 & 0.41 & 0.57 & 1.43 & 1.44 \\
SD & 0.23 & 0.59 & 0.19 & 0.13 & 0.11 & 0.19 & 0.12 & 0.12 & 0.15 & 0.13 & 0.27 & 0.17 \\
\hline
\end{tabular}

Table 2 The average price and standard deviation of Carola with $80 \mathrm{~cm}$ length and B class in each month of 2009

\begin{tabular}{lcccccccccccc}
\hline & Jan. & Feb. & Mar. & Apr. & May. & June. & July. & Aug. & Sept. & Oct. & Nov. & Dec. \\
\hline Avg. Price & 1.26 & 0.96 & 1.28 & 0.25 & 0.30 & 0.30 & 0.40 & 0.67 & 0.47 & 0.84 & 1.04 & 1.10 \\
SD & 0.31 & 0.50 & 0.47 & 0.12 & 0.10 & 0.12 & 0.21 & 0.36 & 0.17 & 0.19 & 0.27 & 0.19 \\
\hline
\end{tabular}

Table 3 and Table 4 show the classification of daily transaction price fluctuation trends of Carola with 80cm length and B class in May 2008 and May 2009. Among them, the data of May 1st 2008, May 1st and May 28th 2009 are missing.

Table 3 The classification of daily price fluctuation trends of Carola with $80 \mathrm{~cm}$ length and B class in each day of May 2008

\begin{tabular}{llc}
\hline Trends & Date & Total days \\
\hline Up & $\begin{array}{l}\text { May 5th, May 9th, May 13th, May 17th, May 18th, May 20th, May 21st, May } \\
\text { 22nd, May 28th, May 30th }\end{array}$ \\
& $\begin{array}{l}\text { May 2nd, May 3rd, May 6th, May 8th, May 10th, May 11th, May 12th, May } \\
\text { Down }\end{array}$ & 13 \\
Mix & 15th, May 16th, May 24th, May 25th, May 26th, May 27th & \\
\hline
\end{tabular}


Table 4 The classification of daily price fluctuation trends of Carola with $80 \mathrm{~cm}$ length and B class in each day of May 2009

\begin{tabular}{|c|c|c|}
\hline Trends & Date & Total days \\
\hline Up & $\begin{array}{l}\text { May } 6^{\mathrm{m}} \text {, May } 7^{\mathrm{ul}} \text {, May } 15^{\mathrm{ur}} \text {, May } 16^{\mathrm{ut}} \text {, May } 19^{\mathrm{ur}} \text {, May } 20^{\mathrm{ur}} \text {, May } 21^{\mathrm{st}} \text {, May } \\
\text { May } 30^{\mathrm{th}}\end{array}$ & 9 \\
\hline Down & $\begin{array}{l}\text { May } 2^{\mathrm{nu}} \text { May } 3^{\mathrm{iu}} \text {,May } 8^{\mathrm{ut}}, \text { May } 10^{\mathrm{ut}} \text {, May } 11^{\mathrm{w1}} \text {, May } 12^{\mathrm{ut}} \text {, May } 13^{\mathrm{ut}} \text {, May } 14^{\mathrm{w1}} \text {, } \\
\text { May } 23^{\mathrm{rd}} \text {, May } 26^{\mathrm{th}} \text {, May } 27^{\mathrm{th}} \text {, May } 29^{\mathrm{th}}\end{array}$ & 12 \\
\hline Mix & 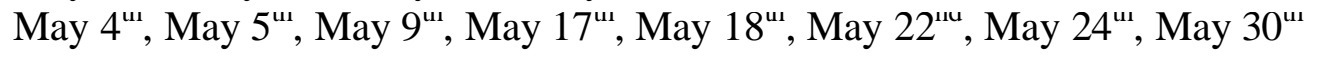 & 8 \\
\hline
\end{tabular}

According to analyze these data, we found that price downtrend of the daily transaction data of Carola with $80 \mathrm{~cm}$ length and B class is in the majority, the downtrend day totaled 25 in May 2008 and May 2008, take up $42.3 \%$ of all the samples. In contrast, the uptrend day totaled 19, take up $32.2 \%$ of all the samples, mix trend totaled 15 , take up $25.5 \%$ of all the samples. These data analysis give us an important conclusion that in contrast with abroad, there is a higher fluctuation level of the fresh produce sequential auction price between transaction days in China. However, there is a certain rule of this fluctuation which is the truncation price downtrend as time passed.

\section{The Factor and Influence Analysis of Price Formation and Fluctuation}

Base on the case summarize above, this article analysis the daily transaction price downtrend of Carola with 80cm length and B class in May 2009, choose the transaction data of May 3rd, May 8th, May 10th and May 23rd to analyze the relevance of fresh produce transaction price with same product, same class and same qualification in order to find out the basic process of auction price formation. Across to set up an ARIMA formulation to make a time series analysis, we get the result as shown in Table 5.

Table 5 The ARIMA analysis of Carola with $80 \mathrm{~cm}$ length and B class

\begin{tabular}{|c|c|c|c|}
\hline Date & Formula & t value & $p$ test of $t$ \\
\hline May $3^{\text {rd }} 2009$ & price $_{t}=0.775$ price $_{t-1}+\alpha_{t}$ & 20.400 & 0.000 \\
\hline May $8^{\text {th }} 2009$ & price $_{t}=0.736$ price $_{t-1}+\alpha_{t}$ & 23.998 & 0.000 \\
\hline May $10^{\text {th }} 2009$ & price $_{t}=0.756$ price $_{t-1}+\alpha_{t}$ & 21.313 & 0.000 \\
\hline May $23^{\text {rd }} 2009$ & price $_{t}=0.578$ price $_{t-1}+\alpha_{t}$ & 7.766 & 0.000 \\
\hline
\end{tabular}

According to Table 5, in the process of daily auction with the produce of same product, same class and same qualification, we found that the last time transaction price has a prominent positive influence on current transaction price. This result reveals the martingale theory in sequential auction also. That is the last time auction transaction price influence the current one. However, based on the influence of multi research variable on price fluctuation, how prominent will the last time auction transaction price influence the current one, remain to further analysis, so we build the following hypothesis:

H1: In sequential auction, the last time auction transaction price has a prominent positive influence on the current transaction price.

In the auction process of KIFA, daily auction start at 21:00 pm every night, the whole auction process last three or four hours. The length of auction time is closely related to the supply amount, every transaction only need several seconds. The tense auction process is a big challenge of attention and reaction capacity to the auction participants. So we build the following hypothesis:

$\mathrm{H} 2$ : The duration of daily auction process has a negative influence on transaction price. 
For all the bidders and suppliers who participate the auction as buyer and seller, most domestic and abroad reference research their valuation or bid based on the hypothesis of risk neutral attitude. Because the risk attitude of participate is random. This article will not make deep research also. But we can find the constitute scale of buyer and seller from their history trading volume, this will react their risk attitude indirectly. This article considers the history trading volume has certain influence on the price fluctuation during auction process, so we built the following hypothesis:

H3: The buyer scale has a positive influence on transaction price.

H4: The seller scale has a positive influence on transaction price.

With the auction process continue the amount of auction goods become smaller. On the contrary of common relation between demand and supply, the supply amount reduce will lead to a weak bidding tend of bidder in sequential auction. That is the smaller scale participate bid more carefully, this will lead to a price fluctuation also. So this article built another hypothesis:

H5: The amount of remain goods has a positive influence on transaction price.

The above five hypothesizes contain the mainly factors which may be influence the price fluctuation of KIFA daily auction transaction price of goods with same class, same standard and same product. We will make an empirical research in the next chapter using multiple regression analysis.

\section{The Empirical Research on the Factors of Price Fluctuation}

According to the five hypothesizes of last chapter and the characters of the data this article research, we choose the transaction price of every auction as the dependent variable of this research. This is the mainly research object also. With the five independent variables of $\operatorname{trn} \operatorname{Pr}$ ice $_{i}^{t}$ means the transaction price of each auction; $\operatorname{trn} \operatorname{Pr} i c e_{i}^{t-1}$ means the transaction price of last auction; durTime $e_{i}$ means the duration from the first auction of the current product; remainSup reans $_{i}$ the remaining supply amount with the auction going on; buyerSum $_{i}$ means the history total buy transaction amount of Carola with $80 \mathrm{~cm}$ length and B class .c means the history total sell transaction amount of Carola with $80 \mathrm{~cm}$ length and B class; $\operatorname{LnRS}_{i}$ means the logarithm of remain supply; buyerType ${ }_{i}$ and sellerType $_{i}$ are constructed by buyerSum $_{i}$ and buyerSum $_{i}$.According to the chosen variables, we build the regression model as formula 5.1 shows.

$$
\begin{aligned}
\text { trn Price }_{i}= & \beta_{0}+\beta_{1} \text { trn Price }_{i}^{t-1}+\beta_{2} \text { durTime }_{i}+\beta_{3}\left[\frac{\text { buyerSum }_{i}}{\max _{i=1.2 \mathrm{~K} n} \text { buyerSum }_{i}}\right] \\
& +\beta_{4}\left[\frac{\text { sellerSum }_{i}}{\max _{i=1.2 \mathrm{~K} n} \text { sellerSum }_{i}}\right]+\beta_{5} \ln \left(\text { remainSup }_{i}\right)+\varepsilon
\end{aligned}
$$

Simplify the formula 5.1 according to the constructed variable; we get the new regression model as formula 5.2 shows.

$$
\begin{aligned}
\text { trnPrice }_{i} & =\beta_{0}+\beta_{1} \text { trnPrice }_{i}^{t-1}+\beta_{2} \text { durTime }_{i}+\beta_{3} \text { buyerType }_{i} \\
& +\beta_{4} \text { sellerType }_{i}+\beta_{5} \text { LnRS }_{i}+\varepsilon
\end{aligned}
$$

To research the influence of every variable on transaction price from different side deeply. We break up the formula 5.2 into formula A and formula B as shown in formula 5.3 and 5.4. We will research the two sub formula separately. 
Formula A:

$$
\begin{aligned}
& t \text { Pri c } e_{l}=\beta_{0}+\beta_{1} \text { t Pric } e_{l}^{t-1}+\beta_{2} d u r T i m \text {. } \\
& +\beta_{3} b \text { u y er } T_{i} y+p \beta_{4} \text { s e l l e r } T_{i} \text { y }
\end{aligned}
$$

Formula B :

$$
\begin{aligned}
\operatorname{trn} \operatorname{Pr} \text { ice }_{i} & =\beta_{0}+\beta_{1} \text { trn } \operatorname{Pr} \text { ice }_{i}^{t}-1+\beta_{5} \text { LnRS }_{i} \\
& +\beta_{3} \text { buyerType }_{i}+\beta_{4} \text { sellerType }_{i}+\varepsilon
\end{aligned}
$$

With the empirical research of regression analysis, we can get the variable parameter of every formula and the testing summary table as shown in table 5.1. This table summarizes and compare analyzes the formula A made up by the data of May 8th and May 23rd 2009 and formula B made up by the data of May 3rd and May 10th 2009.

It contains the constant terms and independent variables, the $R^{2}$ value indicate the goodness of

\begin{tabular}{|c|c|c|c|c|c|}
\hline \multicolumn{2}{|c|}{$\begin{array}{l}\text { Formula \& Parameter } \\
\text { Variable \& Index }\end{array}$} & \multirow{2}{*}{$\begin{array}{r}20090508 \\
\text { Formula A }\end{array}$} & \multirow{2}{*}{$\begin{array}{r}20090523 \\
\text { Formula A }\end{array}$} & \multirow{2}{*}{$\begin{array}{c}20090503 \\
\text { Formula B }\end{array}$} & \multirow{2}{*}{$\begin{array}{l}20090510 \\
\text { Formula B }\end{array}$} \\
\hline Describe & Indicate & & & & \\
\hline \multicolumn{2}{|c|}{$R^{2}$ value } & 0.62 & 0.708 & 0.541 & 0.537 \\
\hline \multicolumn{2}{|c|}{$F$ value } & 131.554 & 78.047 & 84.753 & 68.460 \\
\hline \multicolumn{2}{|c|}{$P$ value of $F$ testing } & 0.000 & 0.000 & 0.000 & 0.000 \\
\hline \multicolumn{2}{|c|}{ VIF mean value } & 0.054 & 0.705 & 0.228 & 0.201 \\
\hline \multicolumn{2}{|c|}{ Sample size } & 327 & 134 & 285 & 241 \\
\hline
\end{tabular}
fit of the formula, the $F$ value indicates the significance level of the formula and the $P$ value indicates the testing result of $F$ value of every formula.

Table 5.1: The summary sheet of each formula parameter and their testing result

The concrete formula made by the two abstract formulas and the data of four specific dates above is shown in the Table 6 .

Table 6 The summary sheet of each formula

Formula name The analysis date Formula

May $8^{\text {th }} 2009$

$$
\begin{aligned}
\text { trn Price }_{i} & =0.176+0.35 \text { trn Price } \\
& +0.03 \text { sellerType }_{i}-0.03 \text { durTime }_{i}
\end{aligned}
$$

Formula A

May $23^{\text {rd }} 2009$

$$
\begin{aligned}
\text { trn Price }_{i} & =0.201-0.063 \text { durTime }_{i}+0.434 \text { trn Price } \\
& +0.062 \text { buyerType }_{i}+0.077 \text { sellerType }_{i}
\end{aligned}
$$

Formula B May $3^{\text {rd }} 2009$

$$
\begin{aligned}
\text { trn Price }_{i} & =-0.069+0.465 \text { trn Price } e_{i}^{t-1}+0.033 \text { buyerType }_{i} \\
& +0.061 \text { sellerType }_{i}+0.014 \text { LnRS }_{i}
\end{aligned}
$$




$$
\text { May } 10^{\text {th }} 2009 \begin{aligned}
\text { trnPrice }_{i} & =-0.068+0.472 \text { trn Price }{ }_{i}^{t-1}+0.026 \text { buyerType }_{i} \\
& +0.042 \text { sellerType }_{i}+0.019 \text { LnRS }_{i}
\end{aligned}
$$

In the chapter 4 of this article, according to the sequential theory and the actual analysis on KIFA auction market we made five hypotheses. Combine with the related independent variable in this chapter and the regression analysis result of four transaction dates and two formulas; we detail the results of the five hypotheses testing as follow.

H1: In sequential auction, the last time auction transaction price has a prominent positive influence on the current transaction price.

From table 4.2 we can find that the values of $\operatorname{trn} \operatorname{Pr}_{i c e} e_{i}^{t-1}$ variable indicate last price are 0.35 , $0.434,0.465$ and 0.472 . This result is consistent with the martingale theory of classics sequential auction theory we have mentioned above.

$\mathrm{H} 2$ : The duration of daily auction process has a negative influence on transaction price.

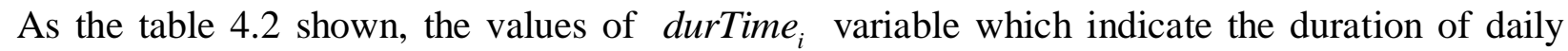
auction process are $-0.03,-0.063$ only in formula $\mathrm{A}$. This means that the duration of daily auction process has a negative significant impact on transaction price. The longer the duration of daily auction process is, the cheaper the transaction price is. It is because after long time tension auction process, not only the attention of trader will be decrease but due to the relation between supply and demand, the price will present a downtrend also. So combine with the theory research and empirical research, we accept hypothesis $\mathrm{H} 2$.

H3: The buyer scale has a positive influence on transaction price.

H4: The seller scale has a positive influence on transaction price.

This article made a quantitative analysis on the indirect factor which will be influence the risk attitude using buyer scale and seller scale. We explain the participant type coefficient according to the transaction amount of Carola with $80 \mathrm{~cm}$ length and B class. From table 4.2 we can find that in the formula $\mathrm{A}$, the regression coefficients of buyerType ${ }_{i}$ indicate the buyer type are 0.052, 0.062; the regression coefficients of sellerType $_{i}$ indicate the seller type are 0.03, 0.077. Overall, the buyer type and the seller type have a positive significant impact. That is the larger the buyer and seller scale are, the higher the transaction price is. So we accept the hypothesis of $\mathrm{H} 3$ and H4.

H5: The amount of remain goods has a positive influence on transaction price.

Because the duration of daily auction process and the independent variable $L_{n R S}$ indicate the logarithm of remain goods are collinear. We only research the influence of $L n R S_{i}$ on transaction price in formula B. As shown in table 4.2, the regression coefficients of $L_{n R S}$ are 0.014, 0.019. It means that along with the process of auction, the remaining auction goods have a positive significant impact on transaction price. This is the mainly result of transaction price decline trend along with the remaining auction goods amount decline.

\section{Conclusion}

This article researches the price fluctuation rules and influence factors with fresh produce sequential auction according to theory and practice, and use the KIFA as sample making empirical research. After choose the research object, research period and the price trend, we make an ARIMA time series auto regression analysis on the process of price forming and confirm that there is a self-relevance between single day transaction price sequences. Base on the above, we build five hypotheses which may be influence the price fluctuation, and build variables according to the hypotheses, analysis them using multiple linear regression, and finally test and verify these hypotheses. However, because of the limitation of data selection in this article, there has more 
theoretical significance and practical significance to research the price fluctuation rules using more other auction markets with new transaction data in the future.

\section{References}

[1] Xi You-Min, Liu Xiao-Jun. Putting Auction Theory to Work: China Machine Press.2000

[2] Milgrom, P. Du Li, Hu Ying-Qi. Putting Auction Theory to Work: Tsinghua University Press, 2006

[3] Dou Li-Mei. The literature review about auction price theory research: Journal of Shanghai business school, 2009, (10):45-51

[4] Chen Jian, Chen Xi-Long, Song Xi-Ping, The buyer's strategy while group-buying auction, Chinese Journal of Management Science,2002,(10):1-7

[5] Zhang Li, The three ideas about flower auction, China Flowers \& Horticulture, 2004, (22):11-12

[6] Li Xian-Guo, Zhang Qian, The operation research of C2C online auction based on the website self-date, China Soft Science,2009 (1) ,112-121

[7] William Vickrey, Counter speculation, Auctions, and Competitive Sealed Tenders, Journal of Finance.16(March 1961), 8-37

[8] Paul R. Milgrom; Robert J. Weber, A Theory of Auctions and Competitive Bidding, Econometrica, 1982, 50(5), 1089-1122

[9] Gerand J, Jan C, Menno P. Declining Prices in the Sequential Dutch Flower Auction of Roses, $1999,6,11$

[10] Chen Yu, Wang Jiang, Yang Bao-Jian. Electronic Auction System Based on Internet:A Case Study of Kunming Flower Electronic Market. Proceeding of the 4th International Conference on Innovation and Management. 2007 